\title{
Medicolegal
}

\section{Coroner overruled: time for reform?}

\author{
CLARE DYER
}

As pressure mounts for a change in the way coroners' inquests are conducted more challenges to inquest verdicts are reaching the high court. Last month, quashing the jury's verdict in an inquest described by Mr Justice Peter Pain as "hopelessly flawed," the court recognised "lack of care" as a possible verdict in appropriate cases and clarified the ambit of the verdict in cases in which medical care is an issue. ${ }^{1}$

The case concerned a 38 year old epileptic and schizophrenic, Keith Hicks, who was detained in Brixton Prison after an assault on his father while suffering paranoid delusions. On 1 March 1985 he was convicted of assault, and a hospital order was made by the court, ordering his detention under section 37 of the Mental Health Act 1983, but he died in Brixton Prison on 12 March, the day he was due to be transferred to hospital. The cause of death given on the necropsy report was status epilepticus.

The Hicks family was concerned about the quality of medical care Keith had received in prison. On 10 January 1985 he had been admitted as an emergency to the Maudsley Hospital. Ten days later he was returned to Brixton, where the treatment started in hospital-phenytoin-was continued. For some days before his death he was unwell. His mother was told that he had had petit mal fits and was not allowed to see him on 6 March. On 7 and 8 March she was again told he was not well. His sister was given the same information on 9, 10, and 11 March. On 11 March he had a grand mal seizure and was put to bed. At necropsy the whole blood phenytoin concentration was $3 \mathrm{mg} / \mathrm{l}$, equivalent to a plasma concentration of $5 \mathrm{mg} / \mathrm{l}$. The question was raised whether that figure indicated that he had not been receiving the proper dose, and the family wanted to know what care he had received between 6 and 12 March.

The inquest, at Southwark Coroner's Court, was presided over by a deputy coroner, Dr David Foster. Before the inquest, and again during the proceedings, lawyers for the family asked for Keith's prison medical records and copies of statements by the hospital and prison staff and those who had treated Keith during his stay in prison. Dr Foster refused the request. The coroner called a prison doctor as a witness, believing that he would be able to give evidence about all the treatment Keith had been given in prison and about the contents of the notes that he had brought to court. As it happened, he had not seen Keith after 6 March, though other doctors had. Counsel for the family wanted to find out which other doctors had seen Keith after 5 March so that they might be called as witnesses. He told the coroner: "I do formally apply that this is the crux of the case, to discover what was wrong with this deceased person over the five days before his death, and that we must, if we are to find out, have evidence either in documentary or oral form about why his family were being told that he was so unwell." The application was disallowed, and, though it was put forward several times, it was refused each time.

At the end of the evidence counsel applied to address the coroner,

London NW1

CLARE DYER, BA, BLS, legal correspondent to submit that the verdict of lack of care should be left to the jury. The coroner refused the application (which he conceded to the high court he was wrong to do, though he believed it was an inappropriate verdict) and left a choice of natural causes, accident, misadventure, ${ }^{\star}$ and an open verdict. The jury brought in a verdict of misadventure.

The high court affirmed Dr Foster's right to refuse to hand over the medical records and statements. "Even assuming that Dr Foster had the records (which it seems he did not) he could not be faulted for not producing them when they were not his to produce without a breach of confidentiality," said Lord Justice Croom-Johnson. (Statements made by prison staff and prison records remain the property of the Home Office.)

The clash between the coroner and counsel for the family stemmed from the coroner's concern that the verdict the jury reached should not seem to place legal liability for the death on the prison staff. A coroner's inquest is a fact finding exercise designed to elicit how, when, and where a person met his death, not to apportion blame. Rule 42 of the coroners' rules reads: "No verdict shall be framed in such a way as to appear to determine any question of (a) criminal liability on the part of a named person or $(b)$ civil liability." The coroner "was obviously concerned that his court should not be treated as a hunting ground for civil litigation," said Lord Justice Croom-Johnson.

It is this limited scope of the coroner's inquest and its inquisitorial nature (in a system where legal proceedings are overwhelmingly adversarial or accusatorial) that have given rise to most of the public criticism of the system. A death in a prison or in police custody naturally sparks off suspicions of a cover up. Relatives want to know how it happened and who, if anyone, was to blame. Yet blame, at least in the sense of civil liability, or criminal liability on the part of a named person, is precisely what the inquest must avoid fixing. When there are allegations of police misconduct and the coroner refuses to investigate them he will inevitably be accused of shielding the police.

Because the process is inquisitorial there are no parties. The family may not insist on calling particular witnesses, though it may ask the coroner to do so. Its only method of eliciting evidence is by questioning the witnesses the coroner calls. With no right to see the statements beforehand the family suffers the disadvantage of not knowing the nature of the evidence that will emerge at the inquest. The coroner is not even obliged to tell the interested parties which witnesses he proposes to call, though he will usually do so. Inquests tend to become trials of strength between the coroner and the lawyers for the interested parties. As Tony Ward of the pressure group Inquest has put it, the existing procedures force the relatives "to fight out what is in reality an adversarial contest with one hand tied behind their backs."

The coroner in the Hicks case took the view that a finding of lack of care would have determined a question of civil liability against the Home Office, which is responsible for Brixton Prison. Was he right? Lack of care was a not uncommon verdict in the past, but it has not

*It is sometimes said that "accident" indicates a happening in which no human control is involved whereas "misadventure" applies to a deliberate, but lawful, human act that unexpectedly takes a turn that leads to death, but in practice no distinction seems to be made. 
often been used recently. Lord Justice Croom-Johnson said the history of the verdict indicated that it was appropriate only to the physical condition causing the death and should not be used to indicate a breach of duty by some other person. "What the verdict of lack of care presupposes is that some other persons had at least the opportunity of rendering care (in the narrow sense of that word) which would have prevented the death. There is no need to go beyond that, although in many circumstances such persons would have had a duty, either legal or moral. The opportunity should have been a real opportunity of doing something effective. This should not be used as a means of levelling disguised criticism at people who do not act in an emergency or take a wrong or inadequate decision in such cases. But if one regards the verdict, at its lowest, as reflecting a missed opportunity, then lack of care without naming names will not be in breach of rule 42 . It should not attribute blame or fault."

Historically, the verdict was the other side of the coin of self neglect. It was used in cases in which the dead person had been neglected and given insufficient nourishment by those caring for him. Since 1984 the list of suggested verdicts in the coroners' rules has included it only as a possible addition to other verdicts such as natural causes or industrial disease, though this is only a suggestion and has no legal force. "If the verdict is proper when the deceased is not given enough nourishment by those caring for him it is also proper if the deceased is not given enough medicine," said $\mathrm{Mr}$ Justice Croom-Johnson. "In those cases where it is thought to be a possible verdict or part of a verdict the jury should receive a very careful direction as to its meaning and the need for a clear causal connection between the lack of care and the death. In the case of Keith Hicks my conclusion is that if there had been evidence of insufficient medical treatment a verdict of lack of care might have been possible." His lordship confirmed that lack of care can be used as a freestanding verdict and not just as an addition to another verdict. The coroner, he said, had overlooked the public importance of having a full investigation in the circumstances of a death in prison. "Once a large gap in the evidence was revealed the proper course would have been to adjourn the inquest in order to fill the gap."

The case raises again the question of whether a coroner's court is the most appropriate forum to investigate the circumstances surrounding death. Most inquests are straightforward and uncontroversial, with no other possible verdict than accidental death or natural causes. In most cases there is no jury. But coroners have neither the training nor the back up to handle difficult, controversial, and highly publicised cases; 25 of the 153 coroners in England and Wales are doctors (though some have a legal qualification), and most of the others are solicitors doing the job part time.

The law reform group Justice identifies one of the problems as the impression, so easily given by the inquisitorial system, that the coroner has already prejudged the issues in the case. ${ }^{2}$ To overcome this Justice suggests grouping existing coroners into areas and appointing a senior coroner for each area. He would be given further training and would handle the controversial cases in his area. In those cases inquests would depart from normal procedure, with a lawyer appointed as counsel to the inquest to present the evidence and the coroner as more of an umpire. Inquest argues that there would be difficulties in identifying which cases are likely to prove controversial and, along with the National Council for Civil Liberties, would like to see the use, in some cases, of the sort of public inquiries that are appointed to look into the deaths of young children from neglect or abuse. ${ }^{3}$

The BMA has recommended that the number of coroners' districts should be reduced and that regional coroners' offices should replace them. ${ }^{4}$ Each region would be under the control of a single coroner with assistant coroners; this organisation, the BMA suggests, would permit a formal training process for coroners and "eventually obviate the necessity of appointing to the post of coroner those with no experience whatsoever in this field." Inquest is also calling for changes in inquest procedures that would give the parties rights similar to those available in a criminal or civil trial: rights to legal aid, to call witnesses, to see witness statements and other relevant documents, and to address the coroner and the jury on the facts.

\section{References}

$1 \mathrm{R} v$ Southwark Coroner, ex parte Hicks, 26 January 1987.

2 Justice. Coroners' courts in England and Wales, 1986. Justice (British Section of the International Commission of Jurists), 95a Chancery Lane, London WC2A IDT. (Price £2.50.)

3 Inquest. Annual report 1985-86. Inquest, Alexandra National House, 330 Seven Sisters Road, London N4 2PJ.

4 British Medical Association. Deaths in the community. London: BMA, 1986.

\section{Medicine and the Media}

$M$ R NORMAN FOWLER denied last week that the Health Education Council has been wound up because of pressure from alcohol and tobacco interests. "That is totally, utterly and completely untrue," he told journalists, adding that "there is not the slightest foundation in that statement."

The Secretary of State was talking to journalists at the phoenix like birth of the new Health Education Authority, whose new chairman is the old chairman of the Health Education Council, Sir Brian Bailey. Mr Fowler's triple (or quadruple) denial may simply reflect the close attention politicians now pay to speech rhythmsor he may believe, like the Bellman in The Hunting of the Snark, that anything said three times becomes true.

The Guardian (19 February) pointed out that Mrs Ann Burdus, one of the two vicechairmen (the other is Mr Alistair Service) announced at the press conference, is a market research expert whose company includes alcohol and tobacco industries among its clients. No other paper I scanned made the same point-but few newspapers go out of their way to annoy those industries anyway.

So there we are, Mr Fowler. The crunch question will be whether any of the remaining members of the new health authority, as yet unnamed, prove to be known as campaigners against tobacco and alcohol. If indeed the new Health Education Authority is to be independent it will carry more conviction among health educators if some of its members are known, committed campaigners against the two most important threats to the nation's health. Would it (or wouldn't it) be surprising if they were not?-TONY SMITH, deputy editor, $B M \mathcal{F}$.

" $\mathrm{I}$ ITAL MILK WARNING-reduced milk intake may lead to calcium deficiency and consequent bone damage," said an advertisement in the London Evening Standard (13 February). "Say no to milk and things could get even blacker," suggested the caption to an advertisement showing a cup of black coffee with a well manicured female hand waving aside a milk jug published in the Daily Mail (17 February). This is the sales pitch adopted by Express Dairy to promote their newly launched calcium supplemented skimmed milk product Vital. Their rivals, Unigate, have fought 